\title{
Rede social empresarial - uma proposta de abordagem interdisciplinar, multiteórica e integrativa
}

\author{
Adriana Landim Quinaud ' \\ http:// orcid.org/ 0000-0001-6986-6070 \\ ' Universidade Federal de Santa Catarina, SC, Brasil. \\ Doutoranda em Engenharia e Gestão do Conhecimento.
}

http:/ / dx.doi.org/ 10.1590/ 1981-5344/ 3818

Esta pesquisa mapeou como as teorias científicas discutem diferentes facetas da Rede Social Empresarial RSE. O objetivo é fornecer um estudo que organize parte do conhecimento existente na interseção de estudos de mídia e ciência da rede. Como um mapa de campo, destina-se a pensar em diversos tipos de vínculos envolvidos em uma perspectiva relacional sobre a RSE. A revisão da literatura identificou 15 teorias, quatro foram selecionadas: a teoria do Capital Social analisa a capacidade da rede de ligar as pessoas entre si; a teoria da Affordance analisa os recursos que a ela oferece; a motivação para participar é analisada através da teoria da Troca Social; e um dos principais desafios das organizações em geral, a localização da expertise é analisada pela teoria da Memória Transativa. Essas teorias não esgotam as possíveis bases teóricas para a conceitualizaçãoda RSE, mas se mostraram de fato apropriadas para explicar importantes processos organizacionais na busca de uma visão mais integral. Por fim, é apresentado o Mapa Conceitual com os principais conceitos-chave relacionados às teorias e suas interconexões no intuito de ajudar a criar uma melhor 
compreensão da integração existente entre elas e servir de instrumento para estatuir o conhecimento criado.

Palavras-chave: Rede social empresarial, Mídia social empresarial, Comunicação organizacional, Laço social, Affordances, Troca social, Memória coletiva.

\section{Enterprise social network - a proposal for an interdisciplinary, multi-theoretical and integrative approach}

This research mapped how scientific theories discuss different facets of the Enterprise Social Network - ESN. The goal is to provide a study that organizes some of the existing knowledge at the intersection of media studies and network science. As a field map, it is intended to think of several types of links involved in a relational perspective on ESN. The literature review identified 15 theories, four were selected: the Social Capital theory analyzes the network's ability to link people to each other; the theory of Affordance analyzes the resources that it offers; the motivation to participate is analyzed through the theory of Social Change; and one of the main challenges of organizations in general, the location of expertise is analyzed by the theory of Transitive Memory. These theories do not exhaust the possible theoretical bases for the conceptualization of ESN, but they have proved in fact appropriate to explain important organizational processes in the search for a more integral vision. Finally, the Conceptual Map is presented with the main key concepts related to theories and their interconnections in order to help create a better understanding of the existing integration between them and serve as an instrument to establish the created knowledge.

Keywords: Enterprise social network, Enterprisesocialmedia, Organizational communication, Social tie, Affordances, Social exchange, Collectivememory. 


\section{I ntrodução}

As mídias sociais depois de conquistarem seu espaco no lazer das pessoas, estão cada vez mais sendo adotadas no ambiente de trabalho. Existem diferentes tipos de mídias sociais, como por exemplo: blogs, wikis, fóruns, microblogging, feeds RSS, sistemas de marcacão social e sites de redes sociais, entre outros (HAKAM, et. al., 2014). A diferenca entre mídia social e rede social é que enquanto o termo mídia vem de meio, que permite a disponibilizacão de informacões e conhecimento, o termo rede vem de ligacão entre as pessoas. O que significa que a mídia social torna o conteúdo acessível para um número ilimitado de pessoas. Por outro lado, como o foco da rede social está na interconexão das pessoas, pode ocasionar a limitacão do número de pessoas que tem acesso a esse conteúdo.

O surgimento da mídia social empresarial-MSE seguiu cinco abordagens de acordo com Turban, Bollou e Liang (2011): (1) usando redes sociais on-line disponíveis publicamente; (2) introduzindo redes sociais empresariais - RSEs internas; (3) criando redes sociais empresariais, de acesso público; (4) aprimorando as tecnologias de comunicacão existentes, com funcionalidades sociais; ou (5) desenvolvendo ferramentas que incluam recursos para suportar aplicativos de redes sociais. A RSE tem sido usada para apoiar a comunicacão, o compartilhamento, a colaboracão e a cooperacão em ambientes virtuais e distributivos, entre outros.

Além da crescente adoção e de sua importância, para Leonardi e Vaast (2016) existem pelo menos quatro razões pelas quais os funcionários deveriam prestar atenção nessas tecnologias: (1) ao contrário da maioria das tecnologias de comunicação adotadas em larga escala (por exemplo, e-mail e intranets), as mídias sociais têm ignorado o departamento de tecnologia da informação (TI). Como aplicativos simples baseados na web são hospedados na nuvem o que torna fácil para gerentes adquirir licenças e adotar suas próprias tecnologias; (2) como demonstraram Treem e Leonardi (2013), ao contrário da maioria das outras tecnologias utilizadas no local de trabalho, as mídias sociais se tornaram populares fora do uso nesse ambiente. Em outras palavras, as pessoas as usavam muito antes de as organizações se interessarem e, portanto, estão confortáveis com o seu uso; (3) o conteúdo compartilhado é gerado pelos funcionários, portanto, depende da sua participação. O que denota que estão cada vez mais ganhando voz; e (4) o conteúdo compartilhado é visível para quase todos. O que significa que os usuários podem transmitir mensagens em toda a organização de maneira impossível antes da introdução das mídias sociais no ambiente de 
trabalho. Essas questões marcam o uso de mídias sociais nas organizações como uma das mudanças mais significativas atualmente (LEONARDI; VAAST, 2016).

Mesmo antes da web 2.0, o tema redes sociais nas organizacões já era bastante pesquisado. O estudo de Kilduff e Tsai (2003) questionava se as pesquisas sobre análise das redes sociais eram um conjunto de métodos ou apresentavam uma perspectiva teórica única. Eles identificaram o papel da teoria na pesquisa sobre rede social e encontraram tres tipos gerais de estratégias: (1) a importacão da teoria de outras disciplinas como a psicologia social; (2) o uso de conceitos teoricamente ressonantes dentro da tradicão da rede social (como a forca dos lacos fracos); e (3) a exportacão de conceitos de rede em teorias organizacionais existentes para criar abordagens híbridas. Os autores alegam que não há leis universais de comportamento organizacional no corpus da literatura. Nessa mesma perspectiva, Monge e Contractor (2003) desenvolveram o modelo de abordagem de rede multiteórico multinível para estudar a criacão, a manutencão e as solucões de redes de comunicacão. Nesse modelo defendem que as teorias devem oferecer prismas diferentes e se concentrar em diferentes facetas do processo em investigacão. Eles argumentam que diferentes famílias de teorias abordam diferentes aspectos e, portanto, mais abrangentes as explicacões podem ser desenvolvidas.

Dessas constatacões, juntamente com a lacuna verificada por Stei, Sprenger e Rossmann (2016) que defendem a necessidade de mapear teorias na proposta de uma perspectiva multiteórica sobre as redes sociais empresariais no ambiente digital. Como uma forma de ajudar a comparar e integrar diversas teorias e a aumentar o poder explicativo. Esse ponto de vista é compartilhado por Leonardi e Vaast (2016) que argumentam que existem poucas estruturas e lentes teóricas para a conceitualizacão e compreensão da forma pela qual as redes sociais são incorporadas e afetam vários processos organizacionais.

\section{Redes sociais empresariais - termos e definições}

Devido ao aumento de sua adocão no ambiente de trabalho, não é surpresa que numerosos autores tenham criado definicões do que seja a RSE. Como um conceito relativamente novo, não apresenta ainda uma definicão clara e precisa. O que significa um campo de estudo recente e em desenvolvimento. Para Wehner, Ritter e Leist (2016) ainda não há uma conformidade sobre qual terminologia usar para esse fenomeno social. Em seu estudo, identificaram alguns termos utilizados na literatura, mas que não os limitam como: Enterprise Social Software, Corporate Social Software; Corporate Social Network; Enterprise Social Networking Sites; Enterprise Social Media, Enterprise 2.0, entre outros. Para eles 
esses termos não são substitutos reais uns dos outros, mas se referem ao mesmo fenomeno e o diferem principalmente pelo tempo em que os termos foram introduzidos ou pelo seu escopo inicial. Esteestudo constatou o termo Enterprise Social Network como sendo o mais usado. Assim, o termo foi traduzido para o portugues como rede social empresarial e adotado para apoiar o seu processo de consolidacão e principalmente por enfatizar o aspecto relacional.

MacAfee (2009) foi um dos primeiros a definir a RSE quando cunhou o termo Enterprise 2.0 para descrever uma tecnologia social baseada em uma colecão de tecnologias da web 2.0 que facilita a comunicacão, a colaboracão e o compartilhamento de conhecimento entre os funcionários dentro de uma organizacão. As RSEs podem ser usadas com dois propósitos: o público (acessíveis a qualquer usuário) e o privado (exclusivos para funcionários). O primeiro envolve a RSE sendo usada como ferramenta de comunicacão com partes externas à organizacão, como relacionamento com clientes, fornecedores e o público em geral. $\mathrm{O}$ segundo é quando a RSE é usada para fins de comunicacão interna e interacão social. Há, portanto, diferencas entre uma mídia social para relacionamento (aberta) e outra organizacional principalmente quanto ao seu objetivo de uso. A mídia com objetivo social foca no relacionamento interpessoal, sendo que qualquer interessado pode participar bastando que crie uma conta. No meio organizacional há fatores que influenciam as interacões, como normas coletivas e organizacionais, questões políticas e legais, dinamicas de poder, motivacões, usos, dentre outros fatores (ELLISON; GIBBS; WEBER, 2015).

Riemer e Scifleet (2012) postularam que a segunda onda de tecnologia social trouxe as RSEs que apresentam um espaco digital verdadeiramente interativo e colaborativo que coloca enfase nos relacionamentos sociais, na comunicacão, na conversacão e no compartilhamento ad hoc. Sharma (2014) a define como redes sociais privadas que ajudam os funcionários a se comunicarem, a engajar e a inovar em departamentos, locais e processos de negócio. Podem ser vistas como intranets corporativas modificadas que permitem a colaboracão ascendente, aumentando a conscientizacão e quebrando sigilos em grandes organizacões. Mas a definicão mais utilizada, constatada pela revisão é a de Leonardi, Huysman e Steinfield (2013), denominada Enterprise Social Media como plataformas que permitem aos funcionários se comunicarem com colegas específicos ou transmitir mensagens a todos na organizacão; indicar explicitamente ou implicitamente parceiros reais de comunicacão; publicar, editar e enviar textos e arquivos ligados a eles mesmos ou a outros; ver mensagens, conexões, textos e arquivos, editados e classificados por qualquer pessoa na organização a qualquer momento. 
Os autores justificam sua definicão porque, ao contrário dos usos externos de redes sociais que utilizam plataformas públicas, a maioria das organizacões implementam uma plataforma integrada de mídia social para comunicacões internas com várias funcões. Por exemplo, a maioria das plataformas internas imita em aparencia, sensacão e funcionalidade os sites de redes sociais públicos como o Facebook. Mas embutido na plataforma, muitas vezes encontra-se blogs e wikis, assim como, recursos através dos quais a marcacão social e o compartilhamento de documentos podem ocorrer. Assim, quando se fala de tecnologias sociais utilizadas para a comunicação interna, faz menos sentido distinguir entre ferramentas como redes sociais, microblogging e rotulagem social, e mais sentido tratar essas ferramentas individuais como parte de uma plataforma integrada.

O aumento do uso das mídias sociais no local de trabalho coincide com o aumento da transparência social. Leonardi (2014) define a transparência social como a visibilidade da comunicação. E essa visibilidade é permitida por dois mecanismos: a transparência das mensagens e a translucidez da rede. A transparência da mensagem é definida como a capacidade de ver o conteúdo das mensagens que outra pessoa troca com um parceiro de comunicação e está ligada ao aumento da capacidade das pessoas de identificar com precisão "quem sabe o que" na organização. A translucidez da rede como a capacidade de ver laços de rede entre colegas de trabalho e está ligada a aumentos significativos na capacidade das pessoas de identificar com precisão "quem sabe quem". Por exemplo, um vidro obscurecido permite que alguém veja a forma de um objeto sem discernir o que é esse objeto, por analogia os usuários de redes sociais podem ver que uma pessoa tem uma ligação com outra pessoa, mas não podem conhecer a força ou a natureza desse laço. Através da precisão do metaconhecimento que engendraram a transparência da mensagem e a translucidez da rede mostraram aumentar a capacidade de inovação através da recombinação do conhecimento em diversos domínios de prática e reduzir a duplicação de trabalho, ajudando as pessoas a aprender o que os outros estavam fazendo e apropriando suas tarefas para reduzir a carga de trabalho (LEONARDI, 2014).

As formas tradicionais de comunicação frequentemente envolvem canais formais como memorandos ou sistemas de intranet. O e-mail e os sistemas de mensagens instantâneas permitiram o envio de conteúdo selecionado para alguns de forma mais informal. A mídia social empresarial, no entanto, habilitou qualquer funcionário a contribuir e a compartilhar seu próprio conteúdo para todos na organização. 


\section{Procedimentos metodológicos}

\subsection{Revisãobibliográfia sistemática integrativa}

A revisão integrativa foi realizada em publicacões dos últimos 10 anos. A escolha para o início do período em 2007 foi devido ser a partir desse ano que comecam a ser intensificadas as publicacões sobre o contexto específico da RSE. Nesse mesmo ano, por exemplo, foi lancado o Beehiveda IBM uma das principais RSEs estudadas servindo de referencia sobre o tema. Anteriormente, o foco dos estudos estava voltado para as redes sociais disponíveis publicamente, como Facebook e o seu uso para o lazer.

Foram definidos como critérios de busca os campos de pesquisa: título, resumo e palavras-chave. As bases de dados utilizadas foram o Portal de Periódicos da Capes, Scopus e Web of Science. Selecionadas devido à relevancia academica, por conter um expressivo número de publicacões, por ser multidisciplinar e por possuir um vocabulário controlado (menos aplicado a base Web of Science).

Assim, constatou-se que o conjunto adequado de descritores mais promissores (embora não se limitasse a esses) mantiveram o mesmo padrão entre as bases consultadas. Para o Portal da CAPES os melhores descritores foram "enterprise" AND "social" AND "network" AND "theory". A para a base de dados Scopus os melhores descritores foram "enterprise" AND "social" AND "networking" AND "theory". Portanto, apenas uma alteracão do termo "network" para "networking" de uma base para outra fez uma significativa alteracão dos resultados alcancados. Por outro lado, a base Web of Science não difere os resultados entre os termos "network" e "networking", ficando com os mesmos descritores das outras bases.

As buscas nas bases de dados retornaram com os seguintes resultados: Portal de Periódicos CAPES 625 resultados, Scopus (Elsevier) 139 resultados e Web of Science 351 resultados. Na sequencia, foram realizadas às buscas por artigos científicos que atendessem aos seguintes critérios de selecão: a) o artigo devia abordar a temática, rede social empresarial e abordar alguma teoria relacionada a esse contexto específico; b) somente foram aceitos artigos publicados em periódicoscientíficos; e c) o texto completo deveria estar disponível para acesso.

$\mathrm{Na}$ etapa de selecão dos artigosfoi realizada uma leitura criteriosa com base na estratégia de busca definida, verificando-se então a adequacão dos trabalhos aos critérios de selecão. Constatou-se que a grande maioria das publicações, não focou ou nem sequer mencionou alguma teoria para relacionar ao contexto da RSE. O total de publicacões selecionadas foi de 34, que abordaram 15 correntes teóricas. A partir dessa etapa optou-se pelo uso do método de análise temática por ser uma 
abordagem flexível e teoricamente acessível para a análise de dados qualitativos na busca de temas ou padrões.

\subsection{Análise temática}

A maioria das teorias identificadas (12) é da área das Ciencias Humanas. O Quadro 1 representa o mapa termáticodas teorias, com seus respectivos temas, a área do conhecimento de origem do pensamento e os principais autores.

Quadro 1 - Mapa temático das correntes teóricas identificadas

\begin{tabular}{|c|c|c|}
\hline Teoria e Área de origem & Temas/lentes & Autores \\
\hline $\begin{array}{l}\text { Teoria da Rede } \\
\text { Social } \\
\text { (Sociologia) }\end{array}$ & $\begin{array}{l}\text { Interação } \\
\text { Posição da rede } \\
\text { Laços fracos }\end{array}$ & $\begin{array}{l}\text { Centola e Macy, } \\
\text { 2007; }\end{array}$ \\
\hline $\begin{array}{l}\text { Teoria da Troca Social } \\
\text { (Sociologia) }\end{array}$ & $\begin{array}{l}\text { Trocas sociais } \\
\text { Reciprocidade } \\
\text { Relações de interesse }\end{array}$ & $\begin{array}{l}\text { Homan, 58; } \\
\text { Thibaut e Kelley, 59; } \\
\text { Blau, 64,86; } \\
\text { Burns, } 73 .\end{array}$ \\
\hline $\begin{array}{l}\text { Teoria da } \\
\text { Affordance } \\
\text { (Psicologia) }\end{array}$ & $\begin{array}{l}\text { Utilidade } \\
\text { Percepção }\end{array}$ & $\begin{array}{l}\text { Gibson, 1986; } \\
\text { Norman, 1988,1990. }\end{array}$ \\
\hline $\begin{array}{l}\text { Teoria do } \\
\text { Capital Social } \\
\text { (Sociologia) }\end{array}$ & $\begin{array}{l}\text { Confiança } \\
\text { Valor individual } \\
\text { Valor coletivo }\end{array}$ & $\begin{array}{l}\text { Coleman,88; } \\
\text { Bourdieu, 86; } \\
\text { Putmann, 96; } \\
\text { Krackhardt, 92; }\end{array}$ \\
\hline $\begin{array}{l}\text { Teoria da Dependência do } \\
\text { Sistema de Mídia } \\
\text { (Comunicação) }\end{array}$ & $\begin{array}{l}\text { Relações de } \\
\text { Poder } \\
\text { Sistemas Sociais }\end{array}$ & $\begin{array}{l}\text { DeFleur e } \\
\text { Ball-Rokeach, } 76 .\end{array}$ \\
\hline $\begin{array}{l}\text { Teoria da Riqueza } \\
\text { da Mídia } \\
\text { (Administração e } \\
\text { Gestão Org.) }\end{array}$ & $\begin{array}{l}\text { Complexidade } \\
\text { da mensagem } \\
\text { Riqueza do meio }\end{array}$ & Daft e Lengel, 86. \\
\hline $\begin{array}{l}\text { Teoria da Memória Transativa } \\
\text { (Psicologia) }\end{array}$ & $\begin{array}{l}\text { Memória coletiva } \\
\text { Repositórios }\end{array}$ & $\begin{array}{l}\text { Wegner, 85;86;95; } \\
\text { Hollingshead, 98, } \\
\text { 2000, } 2001 .\end{array}$ \\
\hline
\end{tabular}




\begin{tabular}{|c|c|c|}
\hline & Localização & \\
\hline $\begin{array}{l}\text { Teoria da Aceitação } \\
\text { da Tecnologia } \\
\text { (Psicologia) }\end{array}$ & $\begin{array}{l}\text { Local de trabalho } \\
\text { Facilidade de uso } \\
\text { Utilidade percebida }\end{array}$ & $\begin{array}{l}\text { Davis, 89; } \\
\text { Adams, } \\
\text { Nelson e Todd, } 92 .\end{array}$ \\
\hline $\begin{array}{l}\text { Teoria do Design } \\
\text { (Sistemas da Informação) }\end{array}$ & $\begin{array}{l}\text { Uso e apropriação da } \\
\text { RSE } \\
\text { Experiências práticas }\end{array}$ & $\begin{array}{l}\text { Gregor e Jones, } \\
2007 .\end{array}$ \\
\hline $\begin{array}{l}\text { Teoria Cognitiva Social } \\
\text { (Psicologia) }\end{array}$ & $\begin{array}{l}\text { Motivação } \\
\text { Comportamento } \\
\text { Interações } \\
\text { Influências }\end{array}$ & $\begin{array}{l}\text { Bandura, 86; } \\
\text { Kollock, } 99 .\end{array}$ \\
\hline $\begin{array}{l}\text { Teoria da Virtualidade } \\
\text { (Comunicação) }\end{array}$ & $\begin{array}{l}\text { Relação social } \\
\text { Ambiente virtual } \\
\text { Mídia mediada pelo } \\
\text { computador }\end{array}$ & $\begin{array}{l}\text { Walther e Burgoon, } \\
92 ; \\
\text { DeSanctis e Monge, } \\
98 .\end{array}$ \\
\hline $\begin{array}{l}\text { Teoria Gatekeeping da Rede } \\
\text { (Comunicação e } \\
\text { Ciência da Informação) }\end{array}$ & $\begin{array}{l}\text { Identificação } \\
\text { Poder político } \\
\text { Produção de } \\
\text { informações }\end{array}$ & $\begin{array}{l}\text { Barzilai-Nahon, } \\
2008 .\end{array}$ \\
\hline $\begin{array}{l}\text { Teoria do } \\
\text { Controle Social } \\
\text { (Sociologia) }\end{array}$ & $\begin{array}{l}\text { Motivações } \\
\text { Controladores } \\
\text { Controlados }\end{array}$ & $\begin{array}{l}\text { Kirsch, 96; 2002; } \\
\text { Soh et al., } 2011 .\end{array}$ \\
\hline $\begin{array}{l}\text { Teoria da Visibilidade da } \\
\text { Comunicação } \\
\text { (Comunicação e } \\
\text { Gestão da Tecnologia) }\end{array}$ & $\begin{array}{l}\text { Transparência da } \\
\text { mensagem } \\
\text { Translucidez da rede } \\
\text { Quem sabe o que }\end{array}$ & Leonardi, 2014. \\
\hline $\begin{array}{l}\text { Teoria dos Bens Públicos } \\
\text { (Economia) }\end{array}$ & $\begin{array}{l}\text { Recursos coletivos } \\
\text { Uso do bem } \\
\text { Dilema social }\end{array}$ & $\begin{array}{l}\text { Samuelson, 54; } \\
\text { Hardin, } 68 .\end{array}$ \\
\hline
\end{tabular}

Fonte: Elaborado pela autora (2018).

Assim, a revisão demonstrou que uma grande variedade de teorias pode ser usada para desenvolver formulações a respeito da RSE. Em alguns casos, diferentes teorias, algumas usando mecanismos teóricos 
similares, oferecem explicações semelhantes, mas em diferentes níveis de análise. Vale ressaltar, a considerável variação na profundidade do desenvolvimento conceitual e da pesquisa nas diferentes teorias.

As 15 teorias identificadas têm como origem seis campos de pesquisa: (1) duas teorias são exclusivas da área da comunicação, Virtualidade e Dependência do Sistema de Mídia, a teoria da Visibilidade tem origem na comunicação e na gestão da tecnologia e a teoria do Gatekeeping de Rede na comunicação e na ciência da informação; (2) da sociologia quatro teorias, Capital Social, Rede Social, Troca Social e Controle Social; (3) da área da psicologia quatro teorias, Cognitiva Social, Memória Transativa, Aceitação da Tecnologia e Affordance (essa última teve sua origem na psicologia, mas atualmente é bastante abordada pela área de arquitetura, design e no estudo das mídias sociais empresariais); (4) da área dos sistemas da informação a teoria do Design; (5) da área da administração e gestão organizacional a teoria da Riqueza da Mídia, e por fim, (6) a teoria dos Bens Públicos da economia.

\subsection{A escolha das teorias selecionadas}

Monge e Contractor (2003) recomendam que em uma abordagem de rede várias teorias sejam combinadas ao conceituar e examinar empiricamente os fenômenos das redes sociais. Fulk e Yuan (2013) com base nesses autores realizaram um estudo multiteórico no contexto específico da RSE que analisou três teorias, Capital Social, Memória Transativa e Bens Públicos com foco no compartilhamento do conhecimento. Com base nessas ideias e nas 15 teorias identificadas foram selecionadas quatro para compor a abordagem interdisciplinar, multiteórica e integrativa. A teoria do Capital Social e a teoria da Affordance foram as mais pesquisadas. Apesar da teoria do Capital Social ter sido analisada ou apenas mencionada mais vezes, a teoria da Affordance foi estudada com mais detalhes devidoaos trabalhos do pesquisador Paul Leonardi.

Para verificar a questão da formação dos relacionamentos, a teoria do Capital Social foi escolhida para abordar a capacidade da RSE em ligar as pessoas entre si, por enfatizar duas perspectivas: o capital social de ponte e o capital social de ligação. Assim, essa teoria está associada à criação de novas relações e redes sociais que são consideradas as principais características dessa tecnologia (STEINFILED; DIMICCO; ELLISON; LAMPE, 2009; RIEMER; FINKE; HOVORKA, 2015).

A teoria da Affordance vem sendo utilizada por pesquisadores e se mostrado útil para estudar a relação entre as novas tecnologias e práticas sociais para explicar por que as pessoas que usam a mesma tecnologia podem desenvolver práticas de comunicação e de trabalho semelhantes e 
diferentes. Ao tratar dos recursos que a RSE oferece, essa teoria concentra seu olhar na interseção entre os objetivos das pessoas e as características materiais dessa tecnologia, sendo uma perspectiva útil para entender o papel das RSEs nas organizações. Assim, foi escolhida principalmente por oferecer uma perspectiva relacional e contribuir para acompreensão sobre o uso da RSE e a explicar as mudanças nas práticas de comunicação e de trabalho que resultam (TREEM; LEONARDI, 2013).

A teoria da Troca Social foi escolhida porque sua abordagem contempla tanto aspectos de benefícios quanto de custos ao explicar os motivos de espreita e comportamento ativo de usuários da RSE. É conhecido que em qualquer comunidade on-line a maioria dos usuários é formada por pessoas que apenas espreitam e um grupo menor que contribui de forma efetiva com o conteúdo. As pesquisas em geral se baseiam em analisar como e porque as pessoas compartilham seus conhecimentos, mas o maior grupo é menos pesquisado, principalmente no que se refere ao ambiente de trabalho. Assim, a teoria da Troca Social foi escolhida por ampliar a visão da importância dos fatores de custona explicação do comportamento de espreita nessas plataformas (ALARIFI, 2016).

Por fim, o compartilhamento do conhecimento organizacional deve ser aprimorado, mas como isso pode ser realizado continua a ser um desafio. Para melhorar a capacidade de identificar com precisão o metaconhecimento atualizado em tempo real através da RSE, um sistema de Memória Transativa permite as pessoas o acesso a uma base de conhecimento maior e mais complexa do que qualquer pessoa possui sozinha. A teoria da Memória Transativa foi escolhida por abordar a memória coletiva e procurar entender a dinâmica de desenvolvimento de uma equipe. Tal compreensão é importante não só para entender como a RSE pode contribuir para a melhoria da localização da expertise, mas também para todos os que trabalham em equipes e as gerenciam (FULK; YUAN, 2013; NEVO; BENSANT; WAND, 2012).

\section{Análise e discussão das teorias selecionadas \\ 4.1 A lente Affordance: os recursos da RSE}

Os pesquisadores que estudam a relacão entre as novas tecnologias e as práticas sociais encontram grande utilidade no conceito de affordance porque ajuda a explicar por que as pessoas que usam a mesma tecnologia podem se envolver em práticas de comunicacão e de trabalho semelhantes ou diferentes. Atualmente os estudos sobre a relacão entre a tecnologia e a mudanca organizacional enfatizam o caráter relacional das affordances. Nessa visão, as affordances podem mudar em diferentes contextos, mesmo que sua materialidade não. Da mesma forma, as 
pessoas podem perceber que um artefato não oferece possibilidades de acão, percebendo, em vez disso, que restringe sua capacidade de realizar seus objetivos. Com base nessa abordagem relacional, Leonardi e Barley (2008) e Leonardi (2011) argumentaram que as affordances de uma tecnologia frequentemente são as mesmas ou similares em diversas configuracões organizacionais porque as características materiais da tecnologia limitam os tipos de interpretacões que as pessoas podem formar e os usos para os quais ela pode ser colocada (TREEM; LEONARDI, 2013).

Ao definir as mídias sociais descrevendo quais os tipos de comportamentos elas normalmente oferecem, é que os pesquisadores podem ultrapassar as particularidades de qualquer tecnologia e se concentrar nos resultados comunicativos. Além disso, ao enumerar suas affordances pode permitir uma compreensão de quando, por que e como as mídias sociais mudam a prática organizacional. Assim, Treem e Leonardi (2013) categorizaram quatro affordances: (1) visibilidade, (2) persistencia, (3) editabilidade e (4) associacão, encontradas em diferentes mídias sociais empresariais, inclusive nas RSEs.

Estudos sugerem que as mídias sociais oferecam aos usuários a capacidade de fazer seus comportamentos, conhecimentos, preferencias e conexões de rede que eram invisíveis (ou pelo menos difíceis de ver) em visíveis para todos na organizacão. A nocão de visibilidade dos autores está ligada à quantidade de esforco que as pessoas devem gastar para localizar informacões. Se as pessoas percebem que essas informacões são difíceis de acessar, ou não sabem quais informacões existem para elas, provavelmente não irão buscá-las. A este respeito, as informacões sobre os comportamentos de trabalho das pessoas, tarefas, conhecimento ou qualquer outra coisa, embora possa estar teoricamente disponível, podem ser para todos os efeitos, invisíveis. Além disso, os indivíduos podem ser funcionalmente invisíveis para os outros, pois pode haver aqueles que não tem domínio de conhecimento para entender a prática de trabalho de alguém com uma especialidade diferente (TREEM; LEONARDI, 2013).

A affordance de persistencia também foi mencionada como "reviewability" (CLARK; BRENNAN, 1991), "recordability" (HANCOCK; TOMA; ELLISON, 2007), ou "permanence" (WHITTAKER, 2003). Quando uma pessoa faz login (ter acesso a uma conta) em uma rede social, essa informacão permanece disponível para os usuários. Em tecnologias como mensagens instantaneas ou videoconferencias, a conversa normalmente está vinculada ao tempo, e uma gravacão da interacão não existe além do que os participantes se lembram. Como as mídias sociais permitem que conversas persistam após o tempo de suas postagens iniciais, os atos comunicativos podem ter consequencias muito além do seu ponto inicial. Para Erickson e Kellogg (2000), a persistencia abre uma variedade de 
novos usos, pois as conversas podem ser pesquisadas, navegadas, reproduzidas, anotadas, visualizadas, reestruturadas e recontextualizadas, com os prováveis impactos em questões pessoais, sociais e práticas institucionais. Assim como, a persistência pode auxiliar no desenvolvimento de um terreno comum em ambientes comunicativos, o que demonstrou ajudar a transmissão de ideias complexas (CLARK; BRENNAN, 1991). Ter o registro de uma comunicacão anterior pode permitir que as apresentacões de informacões sejam adequadamente contextualizadas e proporcionem às pessoas tempo para entender melhor as conversas (GERGLE; MILLEN; KRAUT; FUSSELL, 2004). Isso porque a informacão permanece ao longo do tempo, ou outro usuário pode ver a comunicacão original e contribuir com outras informacões úteis.

A editabilidade refere-se ao fato de que os indivíduos podem gastar muito tempo e esforco criando e reescrevendo um comunicado antes de serem vistos por outros. A edição também se refere à capacidade de um indivíduo modificar ou revisar o conteúdo já comunicado, incluindo atos diretos, como editar um erro ortográfico ou excluir conteúdo. Os usuários de uma RSE podem corrigir os erros que identificam e o seu público nem ficou sabendo. Assim, o comunicador conserva algum grau de controle sobre o conteúdo após a exibicão comunicativa original (TREEM; LEONARDI, 2013).

Ao oferecer aos indivíduos o tempo para elaborar e compor mensagens, a editabilidade permite uma comunicacão mais proposital que pode auxiliar na fidelidade e na compreensão de mensagens. Dennis, Fuller e Valacich (2008) argumentam que a baixa sincronicidade em um meio de comunicacão é particularmente útil quando o objetivo da organizacão é transmitir informacões ou compartilhar conhecimentos anteriormente desconhecidos. Além disso, a editabilidade permite levar em consideracão o contexto em que a mensagem provavelmente será visualizada e adaptá-la de acordo.

As associacões existem de duas formas: de uma pessoa a outra pessoa e de uma pessoa a um conteúdo. O primeiro tipo, de uma pessoa a outra, mais comumente chamada de "laco social" indica uma relacão explícita, embora sem forca discernível, entre duas pessoas. Por e-mail, a menos que alguém seja incluído em uma troca de comunicacão, há poucas informacões sobre os indivíduos que se comunicam e a natureza do relacionamento. A outra forma de asseociacao é de um indivíduo a uma informacão que ele criou ou reconheceu. Um sistema de banco de dados que abriga documentos pode não mostrar quem contribuiu com informacões específicas, e mesmo que isso seja mostrado, será apenas para aqueles que interagem com esse material. Embora as associacões sejam mais frequentemente conceitualizadas quando iniciadas por atores, as mídias sociais diferem de outras formas de comunicação mediada pelo 
computador, pois as recomendacões são fornecidas pela própria tecnologia. A marcacão social, por exemplo, usa algoritmos para recomendar conteúdo e associacões aos usuários com base em padrões de uso ou contribuicões em formacão (TREEM; LEONARDI, 2013).

Após a análise das affordances é possível concluir que as MSEs diferem de outros meios de comunicacão por oferecerem essas quatro affordances de forma simultanea e consistente em um cenário organizacional. A presenca potencial delas pode oferecer aos usuários maior flexibilidade nas formas em que empregam as tecnologias de comunicacão e representam comportamentos através delas, o que, por sua vez, pode influenciar processos de comunicacão organizacional.

\subsection{A lente do Capital Social: duas perspectivas}

O conceito do capital social implica que redes de relacionamento podem ser úteis para prover acesso a recursos, incluindo informacões e conhecimento. De acordo com essa enfase, as relacões podem ser analisadas através de uma perspectiva interna ou externa. Adler e Kwon (2002) se referem a estas duas visões através dos conceitos de bridging e de bonding. A perspectiva de pontefoca no papel dos indivíduos em promover a ligacão entre diferentes comunidades, de forma a criar uma maior coletividade e garantir que a informacão e o conhecimento possam ser compartilhados. Nessa perspectiva, lacos fracos e redes esparsas são uma fonte de capital social para os atores individuais, que enfatiza os aspectos competitivos na obtencão de acesso à informacão. A teoria de ponte é uma teoria de vantagem relativa, na medida em que o capital social não está disponível para todos os atores de uma rede social, mas concentra-se naqueles com números superiores de relacões fracas ou que ocupam posicões de corretores chave na rede (RIEMER; FINKE; HOVORKA, 2015).

A perspectiva do capital social de ligacão foca no fortalecimento dos lacos internos a uma comunidade, de forma a desenvolver coesão para a busca de objetivos comuns. Essa vertente de pesquisa enfatiza os benefícios das relacões e estruturas de rede para colaboracão e acão coletiva. Em oposicão à teoria dos lacos fracos, Krackhardt (1992) enfatiza a importancia de lacos fortes. Sem desafiar a relevancia dos lacos fracos para o acesso à informacão, o autor argumenta que as chamadas relacões filosóficas são a espinha dorsal para mobilizar acões coletivas. Seu conceito de filosofia enfatiza que os relacionamentos crescem ao longo do tempo envolvendo múltiplas interacões que permitem que os aspectos relacionais e cognitivos da relacão surjam, que compõem a confianca, o terreno comum e conhecimento mútuo.

Com base na nocão de lacos fortes, Coleman (1988) enfatiza o papel das estruturas de rede coesivas na consecucão de um grupo fechado. Ele 
argumenta que um grupo fechado ajuda os atores a limitar os efeitos negativos do comportamento indesejado dos outros e que os grupos que apresentam redes altamente conectadas e coesivas são mais eficazes no estabelecimento e observacão de normas sociais que facilitam acões coletivas e comportamentos colaborativos, enquanto as redes esparsas tendem a falhar observando normas de solidariedade. De acordo com a perspectiva de ligacão, os lacos fortes e as redes coesas são uma fonte de capital social para os atores individuais, na medida em que asseguram a solidariedade, a colaboracão e os comportamentos mutuamente benéficos. Ao contrário do capital social de ponte, o capital social de ligacão pode ser mais compartilhado pelos atores que habitam as mesmas estruturas de rede coesivas (RIEMER; FINKE; HOVORKA, 2015). Durante muito tempo essas teorias foram discutidas de modo competitivo, mas estudos mais recentes demonstraram que ambos, o capital social de ponte e o de ligacão, podem ser interpretados como formas complementares, cada um com seu lugar em momentos e contextos diferentes (RIEMER; FINKE; HOVORKA, 2015).

Alguezaui e Filieri (2010) classificam os benefícios e riscos das duas perspectivas. Na perspectiva de ligacão, os benefícios são a solucão conjunta de problemas, o compartilhamento efetivo de informacões e conhecimento, a confianca, o estabelecimento de normas tácitas de comportamento, a reducão dos riscos associados a comportamentos oportunistas e dos custos de transacão, além do entendimento compartilhado de problemas e solucões. Os riscos associados a esta visão compreendem os custos para a manutencão de relacionamentos, fluxos de conhecimento redundantes e a restricão da capacidade da empresa de explorar novos conhecimentos, através da aversão a conhecimentos provenientes de fora da comunidade. A perspectiva de ponte promove benefícios como o acesso a conhecimentos únicos, o controle do fluxo de informacões, a busca efetiva de conhecimento e a recombinacão de conhecimento entre setores. Os riscos apontados são problemas na acão dos agentes envolvidos, o impedimento a relacões mais frequentes e o baixo entendimento do conhecimento disponível.

A RSE está associada à criacão de novas relacões e redes sociais entre funcionários, que são consideradas as principais características dessa tecnologia. Uma série de teorias sob o guarda-chuva do termo capital social estipulou que as relacões sociais e as redes são valiosas para os indivíduos alcancarem seus objetivos. Estudos iniciais teorizam que a RSE cria capital social através da melhoria da conectividade e de um terreno comum entre as pessoas (LEONARDI; HUYSMAN; STEINFIELD, 2013). Alguns autores argumentam que os indivíduos obtêm benefícios da RSE através do acesso a informacões, encontrando a expertise, 
crowdsourcing de ideias ou recebendo ajuda para resolver problemas (ZHANG ET AL., 2010; RICHTER; RIEMER, 2013).

O estudo de Riemer, Finke e Horvoka (2015) focou na análise da comunicacão da RSE da Deloitte Austrália e através dos dados disponíveis foi possível incorporar tanto os chamados "relacionamentos de interacão" que emergem das trocas de mensagens dos usuários e as "relacões de proximidade" que emergem da associacão de grupos na rede. O estudo estabeleceu como ponto de partida investigar o capital social de ponte e o capital social de ligacão como formas complementares de capital social na RSE. Nesse estudo os autores utilizaram classificacões de desempenho do trabalho de final de ano o que permitiu relacionar as estruturas da RSE com o desempenho do trabalho individual. O objetivo foi investigar se os usuários individuais adquirem capital social de sua participacão na RSE, e se sim, que tipos de capital social, isto é, quais relacões e estruturas de rede constituem o capital social. O estudo mostrou que há evidencias para diferentes tipos de capital social de ligacão, mas não para o capital social de ponte. Embora os indivíduos se beneficiem de interacões repetidas com outros usuários e da participacão em grupos de trabalho coesos, eles não conseguem obter vantagens da informacão competitiva de redes fracas de ego ou em posicões de corretor. Essas descobertas contribuem de forma importante para entender a natureza e os potenciais da RSE para permitir acões coletivas e trabalho colaborativo. Ao mesmo tempo, que confirma os pressupostos que a RSE limita a influencia de indivíduos a favor de maior transparencia das informacões com benefícios para processos de trabalho coletivo de conhecimento. Além da abordagem inovadora, esse estudo tem implicacões parapesquisadores de diferentes áreas do conhecimento por demonstrar como o capital social pode ser estudado empregando dados de comunicacão da RSE.

Em outro estudo, Steinfield, DiMicco, Ellison e Lampe (2009) analisaram a relacão entre o uso de RSE e o nível percebido de capital social dos funcionários e descobriram que a visibilidade e a traficabilidade das interacões de redes sociais no trabalho tiveram um efeito positivo na densidade e nos indicadores de laco-reciprocidade do capital social. Os autores focaram no capital social individual em que as pessoas podem ter quantidades variáveis em virtude de atuarem em diversas estruturas sociais. Em sua abordagem usaram a definicão de capital social de Lin (1999) que o considera como investimentos em relacões sociais por indivíduos através dos quais eles obtem acesso a recursos que aumentam os retornos esperados de acões instrumentais ou expressivas. Nesta definicão, a reciprocidade é um mecanismo fundamental para explicar como o capital social funciona entre os indivíduos. Quando aplicado ao contexto organizacional, esse conceito permite examinar a maneira pela qual as relacões sociais podem facilitar a troca de conhecimento, pois 
permite que os indivíduos localizem informacões úteis e também aproveitem recursos e facam contribuicões para a rede. Neste estudo as RSEs podem ajudar os indivíduos a criar e manter o capital social porque suas affordances técnicas e sociais permitem a interacão e, portanto, a reciprocidade, com uma rede maior de conexões. Essas grandes redes tendem a incluir "lacos fracos", como conhecidos e amigos de amigos, que são mais propensos a fornecer novasinformacões. Esses benefícios estão associados ao capital social de ponte (STEINFIELD; DIMICCO; ELLISON; LAMPE, 2009). Para esses autores, as construcões do capital social de ligacão e do capital social de ponte são igualmente relevantes dentro de uma configuracão organizacional. O de ligacão implica confianca e um sentimento de obrigacão que incentiva a reciprocidade, enquanto ode ponte está associado aos tipos de lacos fracos que facilitam o acesso a informacões não redundantes.Portanto, pode-se perceber que existem tanto evidencias de benefícios obtidos do capital social de ponte quanto o de ligacão, daí a importancia de ambos no ambiente da RSE.

\subsection{A lente da Memória Transativa: a localização da expertise}

O conceito de Memória Transativa - MT foi originalmente usado para descrever conjuntos de diretórios que são usados para localizar, alocar e recuperar conhecimento em pares e pequenos grupos e posteriormente expandido para o ambiente organizacional. Nesse contexto, ajuda a entender como os funcionários localizam e utilizam a informacão com base em sua consciencia de "quem sabe o que" e "quem sabe quem. "Vários estudos ampliaram a teoria da MT para configuracões complexas e ad hoc, como organizacões (NEVO; BENSANT; WAND, 2012) e equipes dispersas ou virtuais que incluem membros de várias organizacões (JARVENPAA; MAJCHRZAK, 2008). Estendendo a nocão de MT além de grupos e pares, autores especularam sobre como as organizacões pode funcionar como um sistema de memória transativa - SMT. Anand, Manz e Glick (1998) formularam um modelo que mostra como as organizacões podem ser percebidas como colecões de MTs. Eles propuseram que certas formas de sistemas de informacão, como intranets, motores de busca, conceitos padronizados e vocabulários, podem ser usados para melhorar o funcionamento do SMT.

O estudo de Nevo, Bensant e Wand (2012) teve como objetivo integrar o conhecimento sobre o uso da metamemória no desenvolvimento da MT para entender como a tecnologia pode apoiar melhor o sistema de memória transativa nas organizacões através dos fatores que afetam o seu desenvolvimento, a expertise, a credibilidade e a coordenacão.A mídia social empresarial pode ser amplamente caracterizada pelo apoio à acão coletiva e à interacão social, pela natureza 
de base e pela governanca descentralizada, e pela flexibilidade e portabilidade de sua plataforma. Os recursos da MSE podem suportar a MT através do seu conteúdo e do controle gerado pelo usuário. Por exemplo, ao considerar wikis corporativos e blogs, os dois podem ser uma fonte de informacão para avaliar a experiencia e os conhecimentos dos usuários no domínio publicado, seja através de autoria colaborativa, como é o caso de wikis, ou através de publicacão de conteúdo em blogs. Ambos também estão disponíveis para a criacão automatizada de um diretório de expertise e podem fornecer uma forte indicacão das habilidades de comunicacão de seus autores, além de servir como excelentes fontes de identificacão e construcão de reputacão. Wikis e blogs podem contribuir para percepcões sobre a confiabilidade de uma pessoa. Em particular, essas percepcões podem ser afetadas pelos atributos das comunicacões entre 0 expert e os candidatos a expert. Esses atributos incluem, especificamente, a frequencia da comunicacão, a adequacão das explicacões fornecidas e a abertura da comunicacão. Assim, ferramentas que fornecem comunicacão aberta e frequente do expert em relacão à sua experiencia podem levar a percepcões de confiabilidade se são criados através de um processo colaborativo. Tanto os wikis quanto os blogs podem transmitir, até certo ponto, a disposicão de seus usuários em ajudar. Já que a natureza inerente de todos os aplicativos de MSE é propícia para uma cultura e práticas de ajuda. Além disso, as respostas e mecanismos de comentários embutidos nos blogs podem transmitir informacões sobre a disposicão de seu autor de se envolver em uma troca de conhecimento ativa e conversacional.A avaliacão da confiabilidade também pode ser suportada por informacões sobre as redes sociais dos membros da organizacão. Por exemplo, informacões sobre os lacos de rede que se situam entre um expert e um buscador de experts podem ajudar o investigador a desenvolver a confianca devido ao reconhecimento de lacos comuns. Esses vínculos podem ser construídos com base em funcões organizacionais, relacões interpessoais, interesses compartilhados ou outros fatores. Fornecer informacões sobre a rede social de seus membros também oferece uma boa representacão da capacidade de indivíduos específicos para apontar para outras fontes (ou seja, a consciencia de outros recursos). Além disso, o equilíbrio entre vínculos de rede fracos e fortes e seus diferentes papéis no suporte de acesso ao conhecimento podem ajudar na escolha da experiencia. Em particular, os lacos fortes são vistos frequentemente como mais adequados para apoiar a transferencia de conhecimento tácito, enquanto os lacos fracos são vistos como permitindo o acesso a conhecimentos novos e diversos. $\mathrm{Na}$ verdade, as ideias de uma adocão de ferramentas de computacão social dentro de uma organizacão indicaram que o acesso a lacos fracos foi uma motivacão chave para que usassem a ferramenta. Outras aplicacões 
oferecem maneiras de avaliar os atributos que podem ajudar a suportar o SMT (NEVO; BENSANT; WAND, 2012).

Uma contribuicão deste estudo é que ele examina mais detalhadamente um conjunto de atributos específicos e identifica seu impacto em termos de desenvolvimento do SMT. Os atributos de "quem sabe o que" comumente identificados como a única metamemória mantida no SMT só afetam a medida de especializacão da MT. Foram os atributos que transmitiram percepcões além do assunto e localizacão do conhecimento que produziram o impacto positivo nas medidas de credibilidade e coordenacão. Assim, o estudo oferece uma contribuicão prática importante, identificando atributos relevantes que não só demonstraram afetar a memória transacional dos entrevistados, mas também são bastante operacionais e, em variancia, usados nas aplicacões atuais. Uma variável final examinada foi o contexto da tarefa em termos do processo de MT envolvido. As descobertas mostram que os atributos podem ser percebidos de forma diferente em termos de sua importancia dependendo do processo de memória transacional envolvido (alocacão ou recuperacão) e do usuário individual do sistema (NEVO; BENSANT; WAND, 2012).

Para Fulk e Yuan (2013) a combinacão da teoria da Memória Transativa e suas aplicacões no contexto dos sistemas convencionais de gestão do conhecimento - GC sugerem que a localizacão do conhecimento em nível da organizacão pode ser aprimorada por tecnologias que oferecem pelo menos quatro funcionalidades. Primeiro, os sistemas podem fornecer informacões explícitas sobre conhecimentos, como credenciais ou referencias. Em segundo lugar, os sistemas podem fornecer mecanismos que substituam as pistas informais que são perdidas quando se deslocam de um grupo cujos membros tem contato direto entre si para uma organizacão em que as pessoas podem não se conhecer e não ter a oportunidade de interagir diretamente ou observar processos de interacão. Terceiro, uma vez que a expertise pode estar localizada fora do grupo de trabalho, o sistema pode fornecer informacões sobre os caminhos para esse conhecimento através de outras pessoas ou bancos de dados. Em quarto, os sistemas poderiam oferecer atualizacões contínuas de indícios de localizacão de experts. A primeira funcionalidade para melhorar essa localizacão é oferecida por sistemas GC convencionais, mas os tres restantes são difíceis de realizar através desses sistemas. A RSE pode ser utilizada para essas outras funcionalidadescontribuindo para a compreensão atualizada da distribuicão da expertise relevante. Por oferecer mais componentes informais e sociais em tempo real do que os sistemas de gestão do conhecimento convencionais. Os comentários feitos na RSE, por exemplo, podem transmitir mais opiniões pessoais e/ou usarem uma linguagem 
informal, servindo como fontes indiretas de inferencia da expertise. Os experts identificados através do conteúdo que é compartilhado em tempo real podem ser mais rapidamente atualizados que um diretório de especialistas convencional, que pode ser atualizado apenas periodicamente, como em conjunto com avaliacões de desempenho anual (FULK, YUAN, 2013).Essa affordance de meta conhecimento pode ser usada para tornar a distribuicão doconhecimento mais visível ainda. ARSE combina o uso de dados de conexão social e dados de expertise armazenados para ajudar não só a localizar as pessoas certas, mas também a visualizar um ou mais caminhos para essas pessoas.

\subsection{A lente da Troca Social: motivação para participar}

A teoria da Troca Social - TTS é um dos quadros conceituais mais duradouros e amplamente utilizados. Muitos dos tópicos importantes do comportamento organizacional foram analisados através da sua lente. Foi originalmente desenvolvida por Homans (1950) e Blau (1964), e procura explicar a acão humana por meio de um cálculo de troca de recursos materiais ou de informacão.

Para relacionar a TTS ao contexto da RSE, o trabalho de Alarifi (2016) é de grande relevancia, pois foca na troca de informacões e conhecimento que a visibilidade possibilita para a acão, isto é, contribuir com a publicacão de conteúdos desenvolvendo um comportamento poster (ativo), ou apenas ficar acompanhando as publicacões dos demais em um comportamento lurker. Um problema recorrente da RSE é manter um nível sustentável de participacão ativa de seus membros, ela muitas vezes falha se houver pouco ou nenhum contribuinte de conteúdo. Uma das vantagens de classificar os comportamentos de participacão ativa e à espreita é facilitar a compreensão dos problemas associados a cada comportamento, pois reflete a realidade da participacão on-line nas RSEs.

O incentivo a contribuicão é uma área de pesquisa atraente tanto para os academicos quanto para os profissionais. No entanto, poucos estudos foram conduzidos sobre o fenomeno da espreita, particularmente em um ambiente de trabalho. Identificar o comportamento espreitador, entendendo os "membros" que se escondem depois que já foram introduzidos na plataforma e examinando "como" incentivar os membros mais ativos a serem mais ativos, são os desafios mais significativos dessas comunidades. No entanto, pesquisadores concentraram-se em grande parte no comportamento do ativo, no "como" ou "por que" eles usam ou compartilham seus conhecimentos nas RSEs, sem considerar os motivos e comportamentos de uso do grupo de usuários maior, os lurkers (ALARIFI, 2016).

Compreender o comportamento desses grupos, bem como os principais benefícios percebidos que encorajam a publicacão e as possíveis 
barreiras que fazem com que os membros apenas leiam são cruciais para abordar o problema da participacão. Na área dos Sistemas da Informacão, muitos estudos foram realizados para determinar por que, como e em que condicões os funcionários aceitam, usam ou resistem a uma tecnologia. Da mesma forma, uma melhor compreensão do uso (ou não uso) da RSE contribui para que a sua adocão seja bem-sucedida. A participacão de lurkers e posters na RSE é moldadanão apenas por fatores individuais, mas por estímulos organizacionais também(ALARAFI, 2016).

A teoria da Troca Social levou à identificacão de quatro fatoreschave na motivacão para a postagem e os comportamentos espreitadores: o benefício extrínseco operacionalizado usando a "imagem"; o custo extrínseco operacionalizado usando a "perda de poder de conhecimento"; o benefício intrínseco operacionalizado usando o "interesse intrínseco" e o custo intrínseco operacionalizado usando um novo conceito denominado "cumprimento percebido". A participacão on-line é operacionalizada em termos de medidas de quantidade como o tempo gasto, número de visitas, número de postagens e comentários ou conteúdos compartilhados. A variável dependente (participacão) é uma variável binária de postagem/espreita para identificar quais variáveis independentes (motivacões da participacão) conduz a qual comportamento. A principal hipótese da TTS é que os indivíduos interagem com os outros com base em sua análise auto interessada dos benefícios e custos esperados dessa troca. Para explicar os fatores relevantes para o benefício e ocusto durante a troca social, o estudo de Alarifi (2016) aborda as motivacões extrínsecas e intrínsecas. Dos muitos modelos que explicam essas motivacões que estimulam e prejudicam as contribuicões em um ambiente corporativo, o modelo de contribuicão do conhecimento de Kankanhalli, Tam e Wei (2005) é o mais usado. Portanto, com base na teoria da Troca Social e no modelo de contribuicão do conhecimento foram elaboradas quatro categorias de variáveis independentes.

Alarifi (2016) adotou a conceitualizacão de "imagem" como o benefício extrínseco da publicacão e a "perda do poder do conhecimento" como o custo extrínseco da espreita. Embora o benefício intrínseco do "gozo em ajudar os outros" seja um fator importante na previsão do compartilhamento de conhecimento no modelo de motivacão dos autores, Alarifi (2016) estendeu esse conceito para capturar aspectos mais amplos do próprio prazer dos usuários. Os indivíduos se envolvem na interacão social porque eles esperam obter recompensas sociais, como respeito ou status. Como um benefício extrínseco, o aprimoramento da imagem tem uma influencia importante nos comportamentos dos indivíduos.

Em uma pesquisa sobre os motivos de não publicar, Preece, Nonnecke e Andrews (2004) identificaram cinco razões principais: (1) pensam que apenas a leitura/navegacão é suficiente, (2) ainda estão 
aprendendo sobre o grupo, (3) acham que eles são úteis sendo observadores altruístas, (4) não há necessidade de publicar e (5) simplesmente não conseguem usar as funcionalidades do software. A "apenas leitura/navegacão é suficiente", foi o motivo principal para apenas espreitar nas comunidades de discussão on-line. Alarifi (2016) conceituou uma nova construcão para explicar o motivo "apenas a leitura/navegacão é suficiente". O autor o conceituou como "perceived fulfilmen", em portugues "cumprimento esperado" como fator de custo que poderia dificultar a participacão do usuário. O "cumprimento percebido" é definido como, na medida em que os membros sentem que suas necessidades de uso da RSE são cumpridas somente pela leitura. Segundo o autor, embora sua construcão possa não se assemelhar a fatores inerentemente intrínsecos (por exemplo, o interesse intrínseco), representa o aspecto intrínseco da percepcão de lurkers de que a atividade de leitura em si é suficiente e significativa e que atende suas necessidades de uso. Portanto, argumenta que o cumprimento percebido é um importante motor de comportamento espreitador nas RSEs. E assim, com base nos argumentos anteriores que ligam os quatro fatores à participacão dos usuários, a seguinte proposicão foi formulada: Os benefícios e custos extrínsecos e intrínsecos percebidos afetarão o comportamento de participacão na RSE, de modo que o custo extrínseco percebido da "perda de poder de conhecimento" e a percepcão do custo intrínseco de "cumprimento percebido" incentivarão o comportamento lurker, e o benefício extrínseco percebido da "imagem" e o benefício intrínseco percebido de "interesse intrínseco" incentivarão o comportamento poster.

Desse modo, os resultados sugerem que: (1) as motivacões dos usuários para publicar são diferentes das suas motivacões para espreitar; (2) as RSEs geralmente são percebidas como sistemas para atividades relacionadas ao trabalho, no entanto, a participacão foi provocada por uma combinacão de fatores extrínsecos eintrínsecos. Isso sugere que as motivacões dos usuários não são mutuamente exclusivas porque eles também percebem a RSE como um ator de entretenimento social; (3) a investigacão de fatores benéficos e de custos fornece uma compreensão mais completa de por que os usuários espreitam ou postam nas RSEs; (4) a influencia dos fatores benéficos da imagem e do interesse intrínseco na criacão de conteúdo foram preditores significativos de participacão; (5) a literatura sugere que o fator de custo do interesse próprio que dificulta a participacão é de fato uma barreira significativa. No entanto, a participacão e os comentários dos representantes da administracão, dos membros da equipe de experts e os gerentes da RSE podem criar um ambiente cooperativo que facilite as preocupacões dos usuários sobre a perda de seus conhecimentos; (6) os resultados do fator de custo 
"cumprimento percebido" sugerem que a construcão referente não é apenas conceitualmente relevante, mas também é empiricamente para o problema da participacão. Os usuários são menos propensos a contribuir quando acreditam que a própria atividade de leitura é suficiente e significativa por si só. Uma possível estratégia para mudar essa percepcão seria a adocão de campanhas para mostrar que suas vozes são importantes e necessárias para que as RSEs sobrevivam e conscientizar sobre o valor da norma de reciprocidade no coletivo. Portanto, é possível concluir que a lente da teoria da Troca Social é apropriada para explicar os fatores benéficos e de custo que motivam os comportamentos lurkers e posters nas RSEs. Particularmente, os resultados ampliam a visão da importancia dos fatores de custo na explicacão do comportamento de espreita nessas plataformas (ALARIFI, 2016).

\subsection{Mapa conceitual}

A Figura 1 apresenta o Mapa Conceitual do estudo com o objetivo de criar uma melhor compreensão da integracão entre as quatro teorias e servir como instrumento para estatuir o conhecimento criado.

Figura 1 - Mapa Conceitual

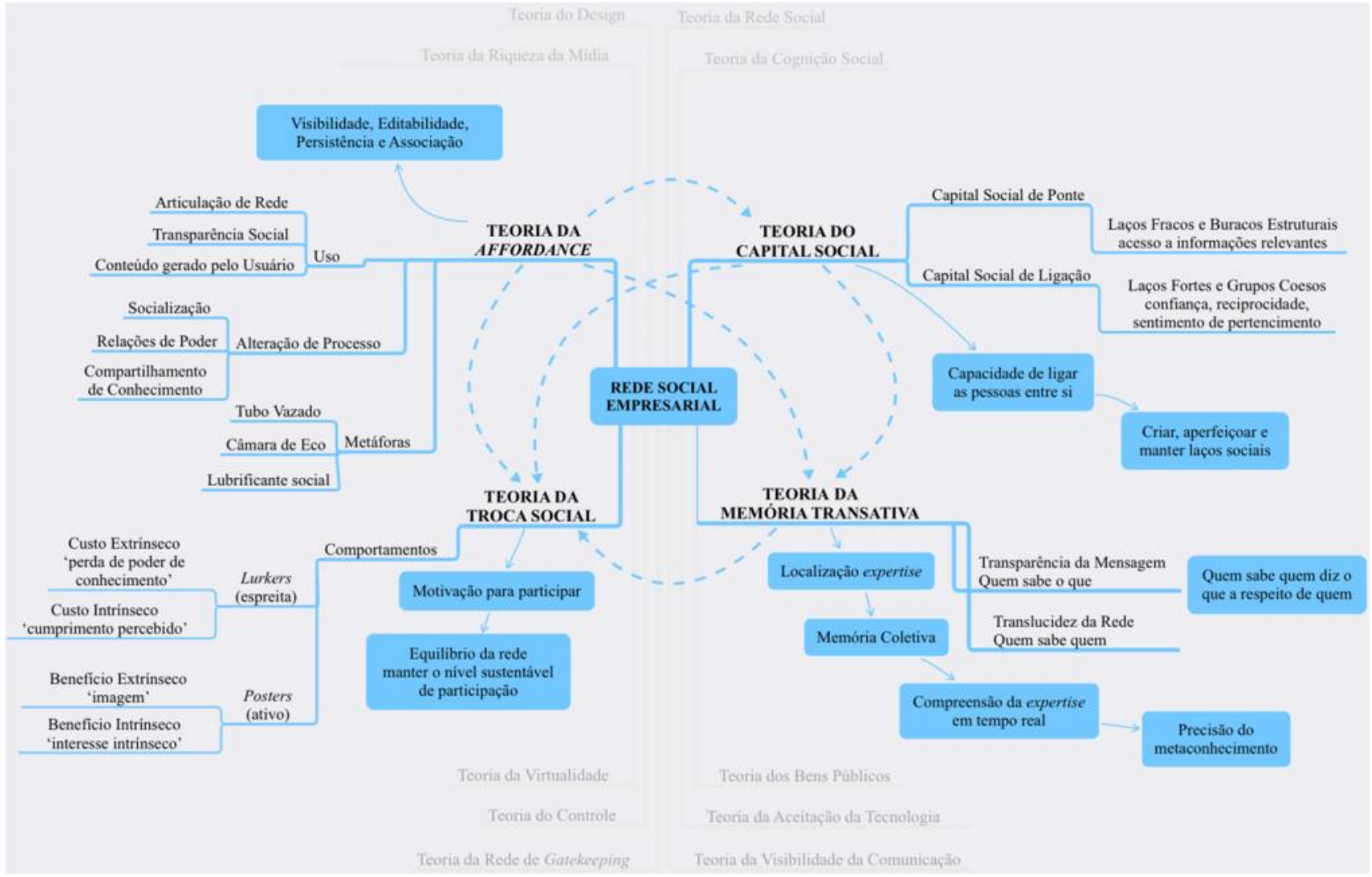

Fonte: Desenvolvido pela autora (2018).

A principal diferenca entre a interdisciplinaridade e a multidisciplinaridade é que a primeira se caracteriza pela intensidade das 
trocas e pelo grau de integracão real das disciplinas no interior de um projeto específico de pesquisa. Para a segunda basta que se justaponham os resultados de trabalhos de mais de um especialista, não havendo integracão conceitual, teórica e metodológica (PACHECO; FREIRE; TOSTA, 2011).

Neste sentido, o Mapa Conceitual visa apresentar os principais conceitos-chave relacionados as quatro teorias e principalmente demonstrar suas integracões. Através da affordance da visibilidade as informacões sobre os tipos de pessoas, comportamentos de trabalho, tarefas, habilidades e conhecimentos estão visíveis para todos na RSE. Em essencia a visibilidade oferece às pessoas a oportunidade de transformar o conhecimento tácito em conhecimento explícito. O aumento do uso da RSE coincide com o aumento da transparencia social que pode ser definida como a visibilidade da comunicacão que é permitida por dois mecanismos: a transparencia da mensagem (quem sabe o que) e a translucidez da rede (quem sabe quem). Isso contribui para a melhoria da localizacão da expertise e na precisão do metaconhecimento em tempo real. As contribuicões podem ser facilmente vistas e localizadas, assim como especialistas identificados formando o sistema de Memória Transativa da organizacão. A capacidade de ver a atividades de um colega de trabalho também influencia as decisões para se comunicar ativamente. O que significa outra conexão que a visibilidade estabelece ao motivar a participacão ativa. Todas essas características resultam no aumento do capital social, tanto na forma de ponte quanto de ligacão, criando mais lacos e fortalecendo os existentes. A articulacão das redes é uma forma primordial para que os usuários criem, aprimorem e mantenham seu capital social.

A RSE ao permitir que conversas persistam ao longo do tempo, incentiva o aumento da participacão. O que gera a possibilidade de rastreamento dos tracos digitais das comunicacões que permite a localizacão de especialistas para colaboracões. A reutilizacão de conteúdos também apoia a formacão de relacionamentos mais estreitos e de comunidades de prática o que representa ganho de capital social. A persistencia do conteúdo pode ser atraente para os recém-chegados na esperanca de aprendersobre a organizacão e acessar informacões que precederam a sua chegada. Como muitos funcionários provavelmente nunca contribuem ativamente, a visibilidade e a persistencia permitem que mais pessoas acessem a informacão fornecida por usuários frequentes.

A editabilidade permite ao comunicador maior flexibilidade o que gera um certo grau de controle editorial sobre o conteúdo. A capacidade de rever e editar são fundamentais para o valor percebido dessa tecnologia, resultando em maior colaboracão (participacão) e um produto 
final mais valioso. Por ser tão fácil publicar e manter conteúdo, os novatos - e não apenas os especialistas - contribuem com informacões específicas. O que pode gerar aumento do capital social entre os membros da RSE e a precisão do metaconhecimento. A RSE oferece uma maneira de tornar as associacões mais explícitas. Pesquisas apontam que funcionários usam essa tecnologia para estabelecer conexões com pessoas que eles conheciam pouco ou até mesmo com desconhecidos. A capacidade de fazer novas associacões entre pessoas e conteúdos também influencia no desenvolvimento do capital social. Portanto, o uso crescente da RSE está relacionado ao aumento do capital social entre relacionamentos novos e existentes. Os usuários visualizam a participacão como uma forma de se sentirem mais perto da organizacão como um todo, tornando-se parte de uma comunidade maior. Além da criacão de lacos pessoais, os funcionários também estabelecem associacões explícitas com o conteúdo encontrado, obtendo acesso informacões relevantes. O que permite que especialistas compartilhem seus conhecimentos. Ao criar associacões explícitas quanto à fonte, qualidade e utilidade da informacão, a RSE pode melhorar o uso de conteúdos e consequentemente a formacão de um sistema de Memória Transativa.

A transparencia social da RSE é permitida por dois mecanismos: a transparencia das mensagens (capacidade de ver o conteúdo que outra pessoa troca com um parceiro de comunicacão) que está ligada ao aumento da capacidade das pessoas de identificar com precisão "quem sabe o que" e a translucidez de rede (capacidade de ver os lacos de rede entre colegas de trabalho) ligada a aumentos significativos na capacidade das pessoas de identificar com precisão "quem sabe quem". Através da precisão desses metaconhecimentos é possível aumentar a capacidade deinovacão da organizacão e reduzir a duplicacão de trabalho. Essa capacidade também permite que os gerentes atribuam as pessoas tarefas apropriadas e melhorem o desempenho do grupo.

As questões mencionadas acima, entre outras, recaptulam algumas das dinamicas de interconexão estabelecidas entre as quatro teorias compondo uma abordagem interdisciplinar, multiteórica e integrativa do fenomeno RSE.

\section{Considerações finais}

Os desafios dos processos da comunicacão intraorganizacional via RSE são importantes porque, mais do que em qualquer outro momento da história, os avancos no século XXI são baseados nas atualizacões constantes das tecnologias e em redes de conhecimento humano.

Ao tratar dos recursos que a RSE oferece, a teoria da Affordance concentra seu olhar na intersecão entre os objetivos das pessoas e as 
características materiais dessa tecnologia, sendo uma perspectiva útil para entender o papel das RSEs usadas nas organizacões. Desse ponto de vista, as RSEs são características constitutivas de todas as acões e processos organizacionais. Isso porque permitem a possibilidade de certos tipos de acão que seriam difíceis ou impossíveis de alcancar sem elas e às vezes restringem outros tipos de acão que seriam desejáveis. Embora essa abordagem ajude a ver que as tecnologias desempenham um papel central, não as coloca em primeiro plano. Em vez disso, a acão organizacional é primária, e as tecnologias que oferecem e restringem as atividades que constituem essa acão são vistas como condicões facilitadoras.Esta revisão apontou que as quatro affordances são relativamente consistentes e podem trazer mudancas substanciais na forma como muitos dos processos de comunicacão são realizados.

Através da teoria do Capital Social-CS foi visto que a RSE cria capital social através da melhoria da conectividade e da criacão de um terreno comum entre as pessoas. Estudos apontam evidencias de benefícios obtidos tanto do capital social de ponte quanto o de ligacão, daí a importancia de ambos. Um estudo não encontrou evidencias do CS de ponte, nem na forma de lacos fracos nem na forma de buracos estruturais, ou seja, os autores concluíram que os usuários não conseguem obter vantagens da informacão competitiva de redes fracas de ego ou em posicão de corretor. Mas dá suporte o CS de ligacão em termos de lacos fortes, emergentes de interacões repetidas e da participacão em grupos de trabalho coesos. Portanto, confirma pressupostos que a RSE limita a influencia de indivíduos a favor de maior transparencia das informacões com benefícios para processos de trabalho coletivo. Por outro lado, outro estudo analisado encontrou mais evidencias do CS de ponte do que o de ligacão, mas os considera igualmente relevantes. O CS de ligacão implica confianca e um sentimento de obrigacão que incentiva a reciprocidade, enquanto o CS de ponte está associado a lacos fracos que facilitam o acesso a informacões não redundantes.

A lente da teoria da Memória Transativa constatou que a teoria e a prática sugerem que a RSE pode contribuir para a compreensão atualizada da distribuicão da expertise relevante. Isso porque oferece mais componentes informais e sociais em tempo real, do que os sistemas de gestão do conhecimento tradicionais. Além do fato de combinar o uso de dados de conexão social e dados da expertise armazenados para ajudar não só a localizar as pessoas certas, mas também a visualizar um ou mais caminhos para acessar essas pessoas (através dos mapas visuais de caminho de rede). A RSE pode oferecer informacões sobre "conversas de conhecimento". A capacidade dessas conversas visíveis para a comunidade poderia substituir até certo ponto a observacão informal subjacente a inferencias de conhecimento em pequenos grupos, ainda 
mais, o usuário não precisa estar presente nos horários da conversa, pois os tracos digitais fazem parte do sistema e podem ser acessados a qualquer momento por pessoas que não participaram, assim como as que fizeram parte.

Por fim, através da lente da teoria da Troca Social foi visto que as motivacões para participar da RSE são diferentes das motivacões da espreita. As motivacões não são mutuamente exclusivas porque os usuários percebem a RSE como sistemas relacionados ao trabalho e ao entretenimento social, assim a natureza dupla pode melhorar a produtividade e proporcionar lazer. A influencia dos fatores benéficos da imagem e do interesse intrínseco na criacão de conteúdo foram preditores significativos de participacão. Enquanto os usuários são menos propensos a contribuir quando acreditam que a própria atividade de leitura é suficiente e significativa por si só. Assim, foi formulada a seguinte proposicão: Os benefícios e custos extrínsecos e intrínsecos percebidos afetarão o comportamento de participacão, de modo que o custo extrínseco percebido da "perda de poder de conhecimento" e a percepcão do custo intrínseco de "cumprimento percebido" incentivarão o comportamento lurker (espreita) e o benefício extrínseco percebido da "imagem" e o benefício intrínseco percebido de "interesse intrínseco" incentivarão o comportamento poster (ativo).

As perspectivas apresentadas oferecem uma base conceitual que permite que pesquisadores continuem investigando o uso da RSE e questionem esse fenomeno e as mudancas associadas a ele. Este estudo pode inspirar mais pesquisas e expandir o conhecimento coletivo em questões sobre a RSE. Em termos mais gerais, dada à taxa de inovacão e mudanca rápida entre os aplicativos de mídia social e tecnologias digitais, espera-se que esta revisão possa ser útil para pesquisadores continuem teorizandoe examinando as novas tecnologias no local de trabalho.

É importante notar que as quatro teorias discutidas não esgotam as possíveis bases teóricas para a conceitualizacão de diferentes facetas da RSE e suas implicacões em importantes processos organizacionais. Existe terreno fértil para a pesquisa que examina a RSE em uma perspectiva multiteórica.

\section{Referências}

ADLER, P..; KWON, S. Social Capital: Prospects for a New Concept. Academy of Management Review, v. 27, n. 1, p. 17-40, 2002.

AGTERBERG, M.; VAN DEN HOOFF, B.; HUYSMAN, M.; SOEKIJ AD, M. Keeping the wheels turning: The dynamics of managing networks of practice. Journal of Management Studies, v. 47, n.1, p.85-108, 2010. 
ALARIFI, A. Posters Versus Lurkers: Improving Participation in Enterprise Social Networks Through Management Interventions. PhD Thesis. Queensland University of Technology, 2016.

ALGUEZAUI S.; FILIERI R. Investigating the role of social capital in innovation: sparse versus dense network. J. Knowledge Management. v. 14, n.6, p. 891-909, 2010.

ALTAMIMI, L. A Lexical Analysis of Social Software Literature. Informatics Economical, v. 17, n.1, p.14-26 2013.

ANAND, V.; MANZ, C.; GLICK, W.An organizational memory approach to information management. Academy of Management Review, v. 23, n. 4, p.796-809, 1998.

BLAU, P. M. Exchange and power in social life.5.ed. New Brunswick and London: Transaction Publishers. 1986. Originally published in 1964.

BURNS T. A Structural Theory of Value, Decision-making, and Social Interaction. Paper read at the Symposium on "New Directions in Theoretical Anthropology," Oswego: New York, 1972.

CLARK, H.; BRENNAN, S. Grounding in communication. In: RESNICK, L. B.; LEVINE, J. M.; TEASLEY, S. D. (Eds. ), Perspectives on socially shared cognition. Washington, DC: American Psychological Association, p. 127149, 1991.

COLEMAN, J. S. Social Capital and the Creation of Human Capital. American Journal of Sociology, n. 94, p. S95-S120, 1988.

DENNIS, A.; FULLER, R.; VALACICH, J. Media, tasks, and communication processes: A theory of media synchronicity. MIS Quarterly, v.32, p. 575600, 2008.

ELLISON, N.; GIBBS, J .; WEBER, M. The Use of Enterprise Social Network Sites for Knowledge Sharing in Distributed Organizations: The Role of Organizational Affordances. American Behavioral Scientist, v. 59, n.1, p. 103-123, 2015.

ERICKSON, T.; KELLOGG, W. Social translucence: An approach to designing systems that support social processes. ACM Transactions on Computer-Human Interaction, v.7, p. 59-83, 2000.

FULK, J.; YUAN, Y. C. Location, motivation, and social capitalization via enterprise social networking.Journal of Computer- Mediated

Communication, v. 19, n.1, p. 20-37, 2013. 
GERGLE, D.; MILLEN, D.; KRAUT, R..; RUSSELL, S. Persistence matters: Making the most of chat in tightly-coupled work. Proceedings of the SIGCHI Conference on Human Factors in Computing Systems, New York: ACM, p. 431-438, 2004.

HAKAMI, Y.; TAM, S.; BUSALIM, A.; HUSIN, A. A review of factors affecting the sharing of knowledge in social media. Science I nternational, v. 26, n. 2, p.679-688, 2014.

HANCOCK, J.; TOMA, C.; ELLISON, N.The truth about lying in online dating profiles. Proceedings of the SIGCHI Conference on Human Factors in Computing Systems, New York: ACM, p. 449-452, 2007.

HOMANS, G. C. The human group. New York: Harcourt Brace, 1950.

JARVENPAA, S.; MAJCHRZAK. A. Knowledge Collaboration among Professionals Protecting National Security: Role of Transactive Memories in Ego-Centered Knowledge Networks. Organization Science, v. 19, n. 2, p. 260-76, 2008.

KANKANHALLI, A.; TAM, B. C.; WEI, K.-K.Contributing knowledge to electronic knowledge repositories: an empirical investigation. MIS Quarterly, v. 29, n.1, p. 113-143, 2015.

KRACKHARDT, D.The strength of strong ties. In: NOHRIA. N; ECCLES, R. G. (Eds.).Networks and organizations: Structure, form and action. Boston: Harvard Business School Press, 1992.

KILDUFF, M.; TSAI, W. Social networks and organizations. New York: Sage, 2003.

LEONARDI, P. M.; BARLEY, S. R. Materiality and change: Challenges to building better theory about technology and organizing. I nformation and Organization, v.18, p.159-176, 2008.

LEONARDI, P. M. When flexible routines meet flexible technologies: Affordance, constraint, and the imbrication of human and material agencies. MIS Quarterly, v. 35, p. 147-167, 2011.

LEONARDI, P. M. Social Media, Knowledge Sharing, and Innovation: Toward a Theory of Communication Visibility. Information Systems Research, v. 25, n. 4, p. 796-816, 2014.

LEONARDI, P. M.; HUYSMAN, M.; STEI NFIELD, C. Enterprise social media: definition, history, and prospects for the study of social technologies in organizations. Journal of Computer-Mediated Communication, v. 19, n.1, p.1-19, 2013. 
LEONARDI, P.; VAAST, E. Social Media and their affordances for organizing: a review and agenda for research, Academy of Management Annals, 2016.

LI N, N. Building a Network Theory of Social Capital. Connections, v. 22, n.1, p. 28-51,1999.

MCAFEE, A. Enterprise 2.0: New Collaborative Tools for Your Organization's Toughest Challenges. McGraw-Hill Professional, Boston, 2009.

MONGE, P..; CONTRACTOR, N. Theories of Communication Networks. Oxford: Oxford University Press, 2003.

NEVO, D.; BENSANT, I.; WAND, Y. Understanding Technology Support for Organizational Transactive Memory: Requirements, Application, and Customization. J ournalof Management I nformation Systems / Spring, v. 28, n. 4, p. 69-97, 2012.

PACHECO, R. C. S.; FREIRE, P. S.; TOSTA, K. C. B. T. Experienciamulti e interdisciplinar do Programa de Pós- Graduacão em Engenharia e Gestão do Conhecimento da UFSC. In: PHILIPPI J r., A.; NETO, A. J. S.

Interdisciplinaridade em ciência, tecnologia e inovação. Barueri: Manole, 2011.

PREECE, J .; NONNECKE, B.; ANDREWS, D. The top five reasons for lurking: improving community experiences for everyone, Computers in Human Behavior, v. 20, n. 2, p. 201- 223, 2004.

RICHTER, A.; RIEMER, K. The Contextual Nature of Enterprise Social Networking: A Multi Case Study Comparison. 21st European Conference on Information Systems ECIS2013, Utrecht, Netherlands, 8th J une 2013.

RIEMER, K.; SCIFLEET, P. Enterprise Social Networking in knowledgeintensive work practices: a case study in a professional service firm. 23rd Australasian Conference on Information Systems, Geelong, 3/ 5 Dec., 2012.

SHARMA, P. Enterprise Social Networks: Engaging Employees and Sustaining Participation. The requirements for the degree of Master of Science in Management Studies, Massachusetts Institute of Technology, 2014.

STEI, G.; SPRENGER, S.; ROSSAMANN, A. Enterprise social networks: status quo of current research and future research directions. 
International Conference on Business Information Systems, p. 371-382, 2016.

STEI NFIELD, C.; DIMICCO, J.M.; ELLISON, N..; LAMPE, C. Bowling Online: Social Networking and Social Capital within the Organization. Proceedings of the Fourth International Conference on Communities and Technologies. New York, 2009.

TURBAN, E.; BOLLOJU, N.; LIANG, T. Enterprise Social Networking: opportunities, adoption, and risk mitigation. Journal of Organizational Computing and Electronic Commerce, v.21, n.3, p. 202-220, 2011.

WEHNER, B.; RITTER, C.; LEIST, S. Enterprise social networks: A literature review and research agenda. Computer Networks, v. 114, p.1$18,2016$.

WHITTAKER, S. Theories and methods in mediated communication. In: A. C. Graesser, M. A. Gernsbacher\& S. R. Goldman (Eds.), Handbook of discourse processes, Mahwah, NJ: Erlbaum, p. 243-286, 2003.

ZHANG, J.; QU, Y.; CODY, J.; WU, Y. A case study of micro- blogging in the enterprise: use, value, and related issues. Proceedings of the 28 th International Conference on Human Factors in Computing Systems. New York: ACM, p. 123-132, 2010. 